\title{
Research on PE Teaching Mode under the Guidance of Healthy School Construction
}

\author{
Qiong Gao \\ Wuhan International Culture University \\ Wuhan, China
}

\begin{abstract}
With the continuous development of society, the demand for talents is increasing, so schools must strengthen their own health construction and improve the efficiency of personnel training. Building a healthy school is the prerequisite for schools to achieve good results in social development. As a course that every student should learn, PE should improve the teaching mode according to the actual situation in order to get the best teaching effect. This article elaborates the meaning of healthy school, puts forward the countermeasure of building a healthy school, and discusses the application of PE mode guided by healthy school construction.
\end{abstract}

Keywords—healthy school; PE teaching mode; construction

\section{INTRODUCTION}

A healthy school refers that a school becomes healthy in terms of spirit, structure, ability and behavior style, which is the premise for the positive development of school. In order to meet the changing needs for talents of today's society, schools should analyze their current situation to adjust their management methods in time. With the continuous development of science and technology, people rely more on high technology and seldom go out to exercise. Many people did not develop the habit of exercise in the student age, and have less and less exercise time after work. Therefore, schools should actively improve PE teaching mode under the guidance of healthy school construction so that students can develop the habit of physical exercises.

\section{MeAning OF HeAlthy SCHOOL}

\section{A. Concept of Healthy School}

In the founding charter in 1948, the World Health Organization made it clear that "health is a perfect state physically, psychologically and socially, rather than merely the state of absence of disease and weakness". That is to say, health is the unity with body, psychology and social function in a perfect state. In the construction of healthy school, the school organization is "the body", and its spirit, behavior and style are "psychology and social function". Whether they are in perfect condition needs us to further consider the purpose of the school so as to examine the perfect state of a healthy school?

All the behavior of school is to follow the advance expectation and promote the perfect and happy life of teachers and students in the school. Therefore, healthy school is able to effectively integrate various functional departments within the campus to maximize the enthusiasm, initiative and creativity of individual education and promote the perfect development of teachers and students. The characteristic of healthy schools is that there are both competition and cooperation among members of the organization, and the school shares the common desire of members. Then the individuals form a series of systems and values to realize this desire.

The construction of healthy school is one of the most important aspects in the development of a school, so schools should always pay attention to whether they are in a healthy state. The school is an organic whole composed of many elements. Only some outstanding majors and backbone teachers are far from enough. Schools should make selfexamination, find their own problems in time, and standardize the behavior within the campus to ensure the healthy development of the school, so that they can achieve the teaching that satisfies the people.

\section{B. Features of Healthy School}

1) Healthy school spirit: School spirit refers to the invisible elements that have a profound impact on the development direction and connotation of the school such as the goal, purpose, concept and value of school. Healthy school spirit means that the school has a sense of social responsibility, a clear purpose of running a school, and the concept of sustainable development, and can reasonably handle the relationship between teachers, students, staff and management departments. Colleges and universities are training bases for students before they enter the society. They not only need to acquire professional knowledge, but also learn the working attitude, to cultivate the correct values and become excellent talents with social responsibility.

2) Healthy school structure: Healthy school structure refers to the health of school in institutional and organizational structure. After the reform and opening up, a large number of private schools have emerged in China. Most of these schools are set up in the form of shareholding system. The clear property ownership makes the right and responsibilities of school clear and standardized, which provides a good foundation for the management of the 
school. The healthy organizational structure of schools refers to the sound, coordinated and perfect campus institutions, which can promote the normal operation of schools. If the organization changes under the competitive environment, it is necessary to adjust the organizational structure in order to achieve organizational goals.

3) Healthy school ability: School ability mainly refers to the decision-making ability, executive ability, innovation ability, and adaptability of school. The high level and high quality of school ability represents the health index of school ability is good. School health can invisibly affect the quality of teaching, and service and other work in schools. Therefore, schools should strengthen the efforts in staff training, enhance the overall ability of individuals through learning, strengthen campus team building and improve the quality of school services to improve the health index of school ability.

4) Healthy school behavior: School behavior refers to the specific actions of school in various activities and dealing with various incidents. Enrollment, teaching, management, organizing activities are the behavior of the school, and all the operational activities of school need to face all teachers, students, workers, peers, society and the public, so the school carry out each activity with kind, serious and responsible attitude. School behavior is reflected through the behavior of all faculty members in the school. When facing the public in the society, their personal behavior represents the behavior of the school. Healthy school behavior refers that each member of the school wins social and public recognition with their own quality and professionalism.

5) Health school style: Healthy School Style refers to the harmonious atmosphere inside the school, which is mainly from the school's mission and long-term implementation of the management and teaching policy that influence the behavior and values of school teachers and students unconsciously, and then they will develop in a positive direction in study, work, and treating others. Although the school style is invisible, it has a significant impact on the development of the school. Only when the school has a good style, it can establish a good image for the school, and cultivate more qualified personnel with eligible ideology and morality [1].

\section{MEASURES TO BUILD A HeAlthy SCHOOL}

\section{A. Leading of Leader's Demonstration}

School leaders play an important role in the construction of a healthy school. The school leaders should have innovative abilities and education wisdom in the school mission, development planning, team building and system improvement so that they can discover and tap the potentials of teachers and students to make they have better development. In schools, school leaders should be able to play a leading and guiding role in demonstrating the school's mental outlook to school staff and students. The school leaders should play a leading role in morality, behavior, and technology and so on, so as to set an example to the school teachers and students [2].

\section{B. To Strengthen Team Building}

First, schools can carry out on-the-job training for teachers. According to the existing teaching level and knowledge ability of teachers, school can develop a scientific and reasonable training plan. The school can implement a resource sharing system, and offer lectures or seminars to enhance teachers' professional competence. Colleges and universities will also strengthen exchanges with foreign institutions and carry out teachers' training abroad through various channels so as to understand the teaching situation in developed countries. In addition, colleges and universities should also pay attention to the introduction of talents by introducing a large number of foreign students, experts and scholars or excellent doctoral and master graduates.

\section{To Improve the Management System}

Healthy schools should have a sound management system to restrain the behavior of teachers and students, making their behavior normative. Rules and regulations of school should pay attention to fairness, humanity and operability. Schools should treat each individual fairly in dealing with affairs, which is the premise of the school rules and regulations. Second, the rules and regulations set by schools should have humanistic concern. The system is to regulate people's behavior, instead of binding them. Finally, only when the rules and regulations set by the school are operable can it play a role in dealing with practical problems [3].

\section{PE TEACHING MODEL UNDER THE GUIDANCE OF HEALTHY SCHOOL CONSTRUCTION}

\section{A. Combining Theory and Practice and Paying Attention to Actual Results}

The PE teaching mode is a teaching system formed by the school to organize and coordinate PE activities. PE teaching not only needs theoretical guidance, but also needs to summarize experience in constant practice. Combining theory with practice can make students learn sports well and develop good sports habits. PE teaching uses theory to guide the practice, and enrich the theory with practice. In traditional PE teaching mode of China, teachers' leading role in class is emphasized too much. Most teachers use the theoretical knowledge as guidance, but fail to adjust the teaching according to actual situation in class, resulting in low participation of students. PE teachers should summarize teaching experience in constant practice, combine theoretical knowledge of PE, formulate reasonable teaching content, and make theory and practice complement each other to improve the teaching efficiency of PE class [4]. 


\section{B. Applying Differential Teaching for Individuals and Paying Attention to Stratified Guidance}

PE teaching should take students as the center, and attach importance to the dominant position of students in the PE class. Each individual has different development, so PE teachers should be able to recognize the existence of differences among individuals, pay attention to differences and respect differences. Based on difference of each student, Differential teaching mode for individual should be applied and reasonable teaching plans should be formulated. The idea of individualized teaching first originated from Socrates in ancient Greece. His teaching idea is to let students get contradictory conclusions with their own ideas through inspiring and raising questions. The students cannot solve the problem and finally accept the conclusion led by teachers. However, the differential teaching mode for individual in PE teaching is to teach according to the different situations of students, arouse students' interest in sports through PE teaching, and develop good physical exercise habits in PE class. Interest is the source of students' in-depth study of sports. Therefore, teachers should pay attention to the training of individual students in the process of teaching so that sports can meet their personal development needs, serve their personal hobby and make students get interested in sports [5].

\section{Sports Situation Teaching Should Pay Attention to Suiting the Practice}

PE situation teaching mode is a kind of teaching mode where teachers can improve students' enthusiasm for learning PE by setting relevant situation, application fields, and sports equipment according to teaching contents and students' actual conditions. The main problem of PE situation teaching mode is how to create the right situation so that students can follow the teacher to experience the charm of sports. The main way that PE teaching creates a situation is to play games. Teachers should have a clear purpose of teaching when applying the game method, and precisely organize teaching activities according to the teaching task to let students to participate. When applying the PE situation teaching mode, teachers should pay attention to the cultivation of students' good sports habits, and make them develop the good habits of loving physical exercise, which is contribute to the healthy development of students' mind and body [6].

\section{Happy PE Teaching Pays Attention to Lifelong Education}

In the teaching process, teachers should apply the mode of happy PE teaching, which is applying appropriate teaching methods to enable students to be happy in the process of learning PE based on the means of sports. This kind of PE teaching mode can effectively improve the teaching efficiency of PE class, improve the students' interest in learning PE and cultivate students to develop the habit of exercise. Happy PE teaching must attach importance to the dominant position of students in PE class, promote students to study PE actively, and make students think actively in PE class, put forward questions and make bold innovations. PE teaching should not be mandatory, it should let students take the initiative to learn sports, and enjoy the fun of sports in learning process. Schools can set a variety of sports teaching programs, such as basketball, taekwondo, aerobics, and roller skating, etc., so that students choose what to learn according to their own interests. Using interest to guide students in sports learning and improving the teaching efficiency of PE class to the maximum extent can help students develop the exercise habit [7].

\section{CONCLUSION}

To sum up, in the process of building a healthy school, schools should pay attention to the exemplary leading role of leadership, strengthen the team building and improve the management system so that the school can attain the spirit of health, structure, ability, behavior and style. The school can select the reasonable teaching mode to bring great convenience to PE teaching. However, PE teachers should understand the actual situation of students, select the appropriate teaching mode according to class teaching tasks, and cultivate students' interest in studying PE to make students develop good physical exercise habits.

\section{REFERENCES}

[1] Xu Ying. Discussion on school health construction. Journal of Shanxi Coal-mining Administrators College, 2008, 21 (1): 83.

[2] Yang Yong, Zhang Shiya. How to build a healthy school. National doctoral student education, 2007.

[3] He Min. Healthy campus construction and school education. Health Education and Health Promotion, 2010 (02): 142-144.

[4] Wang Wenhua. Research on PE Teaching Mode. Journal of Luohe Vocational and Technical College, 2013, 12 (5): 195-196. Yuan Xinhui. Research on the Application of PE Teaching Mode China Science and Technology Review, 2011 (25): 146.

[5] Li Xiaoxia, Lao Ying Chao. Research on PE Teaching Mode. reading and writing, 2008,5 (6): 74-75.

[6] Gong Zhiwei. Happy PE teaching in physical education. education Science (cited), 2015 (15): 297. 